\title{
The Transition to a Coresidential Partnership: Who Moves and Who Has the Partner Move In?
}

\author{
Sandra Krapf ${ }^{1}$ (D) Clara H. Mulder ${ }^{2} \cdot$ Michael Wagner $^{3}$
}

Received: 25 May 2020 / Accepted: 5 July 2021 / Published online: 11 July 2021

(C) The Author(s) 2021

\begin{abstract}
Moving into a joint household is an important step in the process of union formation. While a growing body of literature investigates differences between those couples who start coresidence and those who do not, we know little about the likelihood of moving upon the start of coresidence. The aim of this paper is to investigate how individual and couple-level characteristics are associated with moving, or having a partner move in, at the start of coresidence. We use data from 10 waves of the German Family Panel pairfam for those who started coresidence $(n=983)$ and estimate logistic regression models of moving versus having a partner move in. The respondents in the sample are quite young with a mean age of 27. For long-distance relationships, those with a higher level of education than their partner and women who were living in close proximity to their parents were less likely to move. In short-distance relationships, respondents living in the parental home or in crowded housing were more likely to move than those living in uncrowded housing. In contrast with previous research, we did not find that women were more likely to move than men. Our results highlight that factors like educational resources, housing demands, and local family ties have differential effects on moving decisions at the start of coresidence depending on the distance moved.
\end{abstract}

Keywords Coresidence $\cdot$ Union formation · Relocation · Migration

Sandra Krapf

skrapf@mzes.uni-mannheim.de

Clara H. Mulder

c.h.mulder@rug.nl

Michael Wagner

mwagner@wiso.uni-koeln.de

1 Mannheim Centre for European Social Research, University of Mannheim, Mannheim, Germany

2 Population Research Centre, Faculty of Spatial Sciences, University of Groningen, Groningen, The Netherlands

3 Institute of Sociology and Social Psychology, University of Cologne, Cologne, Germany 


\section{Introduction}

The transition to coresidence is a crucial event in the process of partnership and family formation. Although an increasing share of couples in many western European countries have a child before they marry, the vast majority of couples live in a joint household before a child is born (Kiernan, 2001; Mikolai, 2017). A growing number of studies have investigated which individual and couple characteristics are related to the probability of starting a joint household versus remaining in a living-apart-together relationship or separating (Krapf, 2018; Régnier-Loilier, 2016; Sassler et al., 2016; Wagner et al., 2019). However, hardly any studies have investigated the question of who moves at the start of coresidence and who has their partner move in (Brandén \& Haandrikman, 2019, for an exception). There are some studies addressing moving upon marriage (e.g.Fan \& Huang, 1998; Mulder \& Wagner, 1993), but these studies do not take into account the characteristics of both partners.

The issue of who moves upon coresidence is important because the partner who moves might be in a less advantaged position than the partner who does not. With regard to long-distance moves, previous research shows that persons who moved for reasons that were unrelated to work, including those who moved in order to live with their partner, had decreasing levels of job satisfaction after the move (Switek, 2016). Moreover, movers might experience difficulties in establishing strong social ties at the new place and have lower levels of well-being (Oishi, 2010). Only with regard to housing satisfaction does relocation seem to have a lasting positive effect (Wolbring, 2017). However, the potential increase in housing satisfaction for the moving partner is likely to be reversed in case of separation. Previous research shows that, in case of union dissolution, an ex-partner who moved in with the other partner at the start of coresidence has an increased probability of leaving the joint home (Mulder \& Wagner, 2012). Because moving after separation is often related to downward mobility on the housing ladder (Feijten, 2005; Lersch \& Vidal, 2014; Mikolai \& Kulu, 2018), the person who moved to the partner's home at the start of coresidence is more likely to bear negative consequences in the event of separation than the other partner.

The aim of this study is to investigate the likelihood of moving upon the start of coresidence by using the German family panel study pairfam. With a focus on partnership processes of young couples, pairfam is among the very few survey datasets that collects data about partnerships before coresidence starts. One drawback of the data is that we only have information about the moves of the main respondent (the so-called anchor), but not the moves of their partners. Ideally, we would like to distinguish between (a) couples in which the anchor stays and has the partner move in, (b) couples in which the anchor person moves into the partner's household and (c) those in which both partners move to a new place. Starting from the assumption that moving is generally more costly than having the partner move in, couples of type (b) and (c) differ: in case (b), only the anchor person bears the cost of moving, while in case (c) both partners do. Because of this limitation, we group together types (b) and (c), and focus on a binary variable 
distinguishing couples in which the anchor person moves from those in which their partner moves in. Our central research question is: Which characteristics are associated with a relocation of the anchor person at the start of coresidence, compared with having the partner move in? Although the answer to this question does not paint a complete picture of who moves at the start of coresidenceone partner, the other partner, or both-it still provides important information on whether one of the partners - the anchor respondent-avoids the cost of moving. The previous study by Brandén and Haandrikman (2019) employs the same type of dependent variable.

Just like the previous study by Brandén and Haandrikman (2019), our study is different from older work on marriage migration in that it considers the characteristics of both partners in a newly formed couple. Compared with Brandén and Haandrikman (2019), a major contribution of our study is that our analysis includes all cohabiting couples, not only those that married or had a child. Furthermore, we analyze a comparably young sample of persons with a mean age of 27. Younger persons in relationships that do not necessarily lead to marriage or parenthood may take different factors into account when deciding who moves at the start of coresidence. First, the initial household and housing situation varies depending on age. Younger persons are more likely to live with their parents (Konietzka \& Tatjes, 2014) or in apartments that are too small to start a joint household. Second, the moving decisions of younger couples might follow more gender-egalitarian patterns than those of older couples. The family migration literature shows that women experience moves that are negative for their individual benefit more often than men because they are expected to do so (Cooke, 2008b). Younger adults that are in a life stage before family formation tend to have less traditional gender role attitudes (Scarborough et al., 2019) and therefore, they might differ in their moving decisions from older adults.

For our statistical analyses, we apply logistic regression models to ten waves (2008/2009-2017/2018) of the German Family Panel pairfam. The sample consists of persons who have started coresidence with their partner since the last interview.

\section{Theoretical Considerations}

The focus of this study is on couples who have experienced the transition from a livingapart-together (LAT) relationship to a coresidential partnership. LAT relationships refer to unmarried partnerships in which the partners have a stable intimate relationship but do not live together (Duncan \& Phillips, 2010; Mortelmans et al., 2015). The majority of LAT relationships can be seen as a stage on the way to making a stronger commitment and establishing a joint household (Liefbroer et al., 2015). Our analysis focuses on those persons who have made this commitment and have started coresidence. Our research interest is to identify the determinants of moving versus having the partner move in at the start of coresidence. Compared with household moves, this is a special case as the partners do not live in a joint household before the move. Still, we expect that the moving decision is made by both partners jointly because the move has consequences for both partners' living situation. We employ theoretical arguments from the family migration and relocation literature. 
From the perspective of microeconomics, couples relocate if the expected gains of relocation on the couple level exceeds the cost (Mincer, 1978). This is the case for both short- and long-distance moves. However, the costs and benefits of moving differ depending on the distance moved. Families making short distance moves often choose to do so because their current dwelling does not fulfill their (future) housing needs (Rossi, 1955). Thus, the likelihood of moving increases with a change of household composition. Indeed, many empirical studies show that moves are associated with life course events, such as childbirth, marriage or divorce (Clark \& Huang, 2004; Cooke et al., 2016; Dommermuth \& Klüsener, 2019; Kulu \& Steele, 2013; Mulder \& Wagner, 1993). Starting coresidence also changes the household composition and practical considerations might play a role when deciding who moves. For example, the dwelling of a particular partner might be too small for a joint household. Therefore, we expect that persons who live in a small dwelling are more likely to move at the start of coresidence compared to persons with a larger dwelling (Hypothesis 1a). If a person lives in the parental home before coresidence starts, the person may prefer to move out of the parental home even if crowding is not a problem because the couple wants to live independently. Persons who live in the parental home are therefore expected to have a higher probability of moving than those living in their own household (H1b).

While these practical reasons are associated with the benefits of moving, moves also incur costs. First, there are the actual moving costs, including the opportunity cost of spending time on arranging the move as well as the direct cost of transporting one's belongings. Second, there may be other costs related to the move, such as the costs of furnishing and home improvement. Third, long-distance moves create considerable indirect costs because they affect the working and social life of the person who moves (Niedomysl \& Fransson, 2014). With reference to social life, a longdistance move entails living farther away from a person's social network of family and/or friends (DaVanzo, 1981; Mulder \& Malmberg, 2014). Although communication technologies have developed rapidly in the last few decades, informal support and face-to-face contacts cannot be transferred to a new region-which represents a cost. We expect that people with stronger local social ties are less likely to move (H2a).

Another local tie that could decrease the likelihood of relocation is homeownership. Unlike renters, owners have to bear substantial transaction costs upon sale of their home (Oswald, 2019). However, our study focuses on a relatively young sample in which only $5 \%$ of respondents own a home. The median age at entry into homeownership in Germany is around the mid-thirties (Angelini et al., 2013), while the mean age in our sample is 27.4 years. Given the limited sample size, we refrained from investigating homeownership as an explanation of moving at the start of coresidence.

Regarding working life, partners who are employed are attached to the local labor market. Such local ties to work should reduce the probability of migrating (Mulder $\&$ Malmberg, 2014). But how do partners decide if they have a conflict of interest, e.g., if both partners are employed and both have a preference for staying in their place? Contradicting classic microeconomic arguments, individuals might be more interested in their own relative power than in total household benefit (Lundberg \& 
Pollak, 1996). In line with this idea, a person would be less willing to move if relocating downgrades her bargaining position (Abraham et al., 2010). The bargaining position of a person is indicated by her relative resources compared to those of her partner. With respect to moving over longer distances at the start of coresidence, we therefore expect that the partner with more relative resources is less likely to move (H2b). Because we lack data about the second partner's moving behavior, we cannot test the effect of relative resources on the moving decisions within a couple. However, we can observe across couples whether a person with more relative resources is less likely to move than a person with fewer relative resources.

The basic notion of the bargaining approach leads to gender-neutral expectations, i.e., the relative position has the same effect for men and for women. However, gender norms may also impose costs on couples that do not comply with them (Lundberg \& Pollak, 1996). Indeed, the gender role approach emphasizes that women tend to support men's career- and job-related migration because they are expected to do so-regardless of their own economic position and prospects (Bielby \& Bielby, 1992; Cooke, 2008a). In contrast to the relative resources idea, the gender role approach suggests that it is not employment or demographic characteristics that affect a woman's bargaining position but the perceived social expectation that the female partner should support her male partner and bear the costs of moving. Deviating from such gender norms may lead to sanctions, and in order to avoid these, women might be willing to move regardless of their relative resources. Following from this argumentation, one would expect that women are more likely to move than men at the start of coresidence (H3).

\section{Previous Research}

As noted in the introduction, previous research that explicitly analyses the moving decision at the start of coresidence is scarce. One Swedish study has analyzed the moves of individuals when they establish a joint household with their partner (Brandén \& Haandrikman, 2019). It should be noted that, due to data limitations, their sample only included couples who eventually had a first common child or got married; short-lived cohabitations are underrepresented. In line with our Hypothesis $2 \mathrm{~b}$, the study showed that a smaller share of relative resources was associated with a higher likelihood of moving at the start of coresidence.

Moreover, in line with Hypothesis 3, the authors found a gendered pattern: the odds of moving at the start of coresidence in Sweden were slightly higher for women, and for long-distance couples (i.e., those who lived more than $50 \mathrm{~km}$ apart before they established a joint household), the median distance women moved was $38 \mathrm{~km}$ farther than the median distance men moved at the start of coresidence (Brandén \& Haandrikman, 2019: p. 445). Other studies on migration around the time of marriage also found indications that women were more likely to move toward men than vice versa (Fan \& Huang, 1998; Mulder \& Wagner, 1993). There is also evidence that two-gender couples tend to live closer to the man's than the woman's parents-likely because the woman moved toward the man (Blaauboer et al., 2011; Løken et al., 2013). 
In sum, the existing literature implies that women are more likely to move at the start of coresidence. However, the papers presented here analyze samples of mainly longer-lasting couples, e.g., those who are married or who are on average older than those in our sample. It remains unclear whether these results extend to the migration decision at the start of coresidence among younger couples (of mean age 27 in our empirical analyses), some of whom might have less stable relationships.

\section{The German Context}

In our analyses, we focus on couples living in Germany. With regard to the housing system, Germany stands out for its comparably low homeownership rate of $51.1 \%$ in 2019 (as compared with the estimated EU28 average of 69.2\%; Eurostat, 2020). Young Germans have weaker incentives to enter homeownership because long-term renting is affordable, secure and accepted (Lennartz \& Helbrecht, 2018). While in Great Britain, for example, entry into homeownership is synchronized with union formation, in Germany it is typically postponed until the arrival of a child (Bayrakdar et al., 2019). This is also reflected in the very low share of homeowners in our data of mainly childless young adults in Germany. Although Germany is often rated as gender egalitarian in international comparisons (Aboim, 2010; Voicu, 2017), the combination of a male breadwinner and a female in part-time employment has been the dominant arrangement of families with young children since the mid-1990s (Trappe et al., 2015). Therefore, we might expect that German women are more likely to move in favor of their husbands' career, while this is less likely to occur in more gender-egalitarian countries, such as Sweden. This idea has been supported in a comparative study of Sweden and Germany (Vidal et al., 2017). The study revealed that in Germany, male-breadwinner and dual-earner couples with a male partner working in a managerial or professional occupation displayed comparatively high migration rates. In Sweden, male-breadwinner families were also more likely to move than other families. But dual-earner couples migrated less often when at least one partner worked in a managerial or professional occupation. The authors interpret this finding as support for the idea that Swedish women are more likely to influence family migration decisions (Vidal et al., 2017).

\section{Data and Methods}

We used 10 waves of the German family panel pairfam, release 10.0 (Brüderl et al., 2019a, b; Huinink et al., 2011). The panel is conducted on an annual basis (data collection between 2008/2009 and 2017/2018) among men and women in three birth cohorts: those who were born in 1991-1993, 1981-1983, or 1971-1973. Within these cohorts, the data collection is based on a 2-stage stratified random sampling procedure. More than $65 \%$ of respondents in our sample live in cities with 100,000 inhabitants or more. Data quality tests suggest that pairfam data are highly representative of the corresponding birth cohorts in the general German population (Brüderl et al., 2020). In our sample, we only include couples in which both partners were at 
least 18 years old. Because our hypothesis 3 focuses on gender differences between partners, we study only two-gender couples. Our units of analysis are 983 individuals that reported that they were living in a LAT partnership in one wave and coresiding with the same partner in the following wave (in an additional analysis we also include couples newly formed between waves - see the last paragraph of the section "Analytical Strategy").

In the first wave, the overall response rate was 37\%, and the panel stability ranged between $73 \%$ and $92 \%$ in the following waves (Brüderl et al., 2020). Panel attrition is a phenomenon faced by many longitudinal data collection projects, and this can lead to biased estimates if respondents drop out from the survey in a systematic way. For our study, this is problematic because respondents are more difficult to track after they move (Müller \& Castiglioni, 2020) and thus drop out of surveys more often than immobile respondents. If movers systematically differ from stayers, increased dropout rates might distort the results of the analyses of moving behaviors. One way to reduce such bias is the use of weights in the statistical analysis (Trappmann et al., 2015). Therefore, we use the longitudinal weights provided by the pairfam team. ${ }^{1}$

\section{Outcome Variable: Moving at the Start of Coresidence}

Theoretically, we are interested in the variable moving at the start of coresidence with regard to both partners. However, in pairfam, information about relocations is collected only for the main respondent, the so-called anchor. Therefore, we focus on the relocation behavior of the anchor at the start of coresidence. In a first step, we identify who has started to coreside with a partner since the last wave. Based on the answers to the questions "In the following, I'll ask you about steady relationships. Do you currently have a partner in this sense?", "Do you live together with [name of partner] in the same dwelling?", "What is your current marital status?", and "When did you get married to [name of partner] or when was your civil union with [name of partner] officially registered?" the pairfam team generated a partnership history for each person. From this, we identified those couples that had an unmarried living-apart-together relationship in wave $t-1$ and reported coresiding with the same partner in wave $t$. All other couples were excluded. In a second step, we used the information about relocation and migration to identify whether a person moved. If a person reported a relocation in the same year as she started coresidence, the outcome variable takes the value 1 . If a person entered coresidence but did not report a relocation, the indicator takes the value 0 . The majority of anchor persons $(64.6 \%$ in the full sample) report that they moved at the start of coresidence (Table 1). This seems plausible as this group comprises those who moved in with their partner as well as those who moved to a third place at the start of coresidence.

\footnotetext{
1 We followed the procedure recommended by the pairfam team; see the do-file published by the pairfam Group (2020).
} 
Table 1 Descriptive statistics

$\begin{array}{lll}\text { Total sample } & \begin{array}{l}\text { Subsample: } \\ \text { long-distance } \\ \text { couples }\end{array} & \begin{array}{l}\text { Subsample: short- } \\ \text { distance couples }\end{array}\end{array}$

Distance to partner before move

Long distance $(1+\mathrm{h}) \quad 25.4$

Short distance $(<1 \mathrm{~h}) \quad 74.6$

Outcome variable: anchor moves

Yes

No

64.6

35.4

43.2

56.8

27.4

Age of anchor person

Age difference

Same age

39.3

26.5

Anchor older

Anchor younger

Educational difference

Same education

Anchor higher

Anchor lower

Difference in employment status

Both full-time

Both other

Anchor full-time, partner other

Partner full-time, anchor other

Children of anchor

No children

1 or more children

Anchor's travel time to parents

Long distance $(1+\mathrm{h})$

Short distance $(<1 \mathrm{~h})$

Anchor's housing situation

Lives with parents

Own household: crowded

Own household: uncrowded

Birth cohort (anchor)

$$
\text { 1991-1993 }
$$$$
\text { 1971-1973 }
$$

Region (anchor)

Western Germany

Eastern Germany

15.0

46.8

39.6

13.5

34.5

27.7

16.7

21.1

89.1

10.9

26.0

74.0

27.8

50.7

21.5

Country of birth (anchor)
69.8

62.8

30.2

37.2

0.136

44.9

42.7

55.1

57.3

0.629

27.3

27.4

41.3

38.6

24.7

27.0

34.0

34.3

0.818

54.3

59.4

23.2

20.8

19.8

0.591

22.5

29.4

36.2

27.6

27.8

21.4

15.1

21.6

20.9

0.271

93.3

87.7

12.3

0.032

6.7

45.1

19.6

54.9

80.5

0.000

24.9

28.8

58.0

48.3

17.1

23.0

0.046

$47.5 \quad 46.6$

40.2

39.4

14.0

0.875

12.3

85.1

15.0

0.991 
Table 1 (continued)

\begin{tabular}{lllll}
\hline & Total sample & $\begin{array}{l}\text { Subsample: } \\
\text { long-distance } \\
\text { couples }\end{array}$ & $\begin{array}{l}\text { Subsample: short- } \\
\text { distance couples }\end{array}$ & $p$ value \\
\hline Germany & 91.1 & 90.4 & 91.4 & 0.775 \\
Other & 8.9 & 9.6 & 8.6 & 736 \\
Number of partnerships & 983 & 247 & \\
\hline
\end{tabular}

Column percentage or means

The anchor is the main respondent in the multi-actor design of pairfam. Short-distance couples are those who had to travel less than $1 \mathrm{~h}$ to meet the partner before coresidence. Long-distance couples are those who had to travel $1 \mathrm{~h}$ or more. Percentages may not sum to 100 due to rounding. Source: pairfam, waves 1-10 (2008/2009-2017/2018). Weighted data (for details of the weighting procedure, see pairfam Group 2020). $p$-values refer to the adjusted Wald test (test of independence with weighted data), comparison of long and short-distance couples

\section{Explanatory Variables}

It seems plausible that relocation decisions are affected by the situation before the actual move. Therefore, in our main analyses we use the measurement of our independent variables in the year before the start of coresidence, i.e., the measurement at time $t-1$. Our first two hypotheses referred to the housing situation before coresidence started. We combine information on housing and living in the parental home into one indicator with three categories: (1) anchor lives with parents, (2) living in one's own crowded home before the move, i.e., one person per room or more-either alone or sharing with others (own household: crowded) and (3) living in one's own household with less than one person per room (own household: uncrowded). In pairfam, the question about the number of rooms was posed as follows: "And how many rooms does this apartment (or this house) have?" In case the respondent found this question unclear, the interviewer instructed her or him to count only the rooms that are larger than six square meters, and that are not bathrooms or kitchens. Thus, the number of rooms refers to the number of bedrooms, living rooms and other rooms, such as workrooms. Based on this, we calculated the ratio of individuals living in the household to the number of rooms.

We used three indicators to assess the effect of an individual's relative resources. We first measure the age difference between the partners. Arguably, higher age is associated with a stronger attachment to a location (Fischer \& Malmberg, 2001) and to further advancement in the labor market career. Both aspects are associated with a reduced likelihood of moving. The category same age includes those partners who are no more than 2 years apart in age, the anchor older category includes couples where the anchor is at least 3 years older, and the anchor younger category includes couples where the partner is more than 2 years older than the anchor. The second measure of relative resources refers to educational difference. We do not have information about partner's income; thus, we use education as a proxy for earning potential. We classified each partner's educational attainment based on the International Standard Classification of Education (ISCED 97) and divided it into 3 categories for 
each partner: low (no or lower secondary school degree), medium (upper secondary and post-secondary [but non-tertiary]), and high (university or college degree). Two partners in the same category were then classified as having the same education. Couples in which the anchor had higher education than the partner were categorized as anchor higher, those in which the anchor had lower education as anchor lower. Our third measure of relative resources is employment difference. Here, we assume that employment is an indication of attachment to the local labor market. A person that does not participate in the labor market has no such attachment and therefore a lower cost of relocating than an employed person. By contrast, a person who is employed full-time is well integrated into the local labor market. We assume that a person in full-time employment has a higher income and greater difficulties in finding an adequate job at a new location; thus, the person has a better bargaining position. By contrast, persons who work part-time or are not employed (including unemployment, parental leave, enrolled in education) are assumed to be less integrated into the local labor market and thus their relative resources with respect to employment are smaller. Both full-time includes couples with two full-time employed partners. By contrast, the category both other refers to couples with two partners who are not employed full-time. Moreover, we distinguish between couples in which the anchor is employed full-time, while the partner belongs to one of the other employment groups (anchor full-time, partner other). In the third category are those couples in which the partner is employed full-time, while the anchor belongs to the other category (partner full-time, anchor other). It would also be interesting to differentiate between combinations of partners who are employed part-time, inactive, unemployed, or enrolled in education which we now group in the other category. However, with more categories, the number of persons in some of the categories were quite small.

We used two measures of local ties. The first is whether the anchor has any children. The literature shows that moving can have negative effects on children's well-being (Coley \& Kull, 2016). Because parents may anticipate these negative effects, they are likely to have a preference to stay in their home (or at least in the neighborhood) when forming a joint household. Our second measure of local ties is anchor's travel time to the closest parent. Parents are a central source (and/or recipient) of social support. Small distances facilitate interaction; thus, parents that live in geographic proximity are associated with a person's immobility (Ermisch \& Mulder, 2019; Hünteler \& Mulder, 2020). We distinguish between those who have to travel $1 \mathrm{~h}$ or more to meet their closest parent from those who have to travel less than $1 \mathrm{~h}$. If a respondent's parents had passed away before the interview this person was categorized into the long-distance group.

As control variables, we included the anchor's gender (in the models that are not separated by gender) and age at time of interview (in years). In order to account for potential changes over cohorts, we controlled for birth cohort, i.e., those born in the years (1) 1991-1993, (2) 1981-1983 or (3) 1971-1973. In Eastern Germany, family behaviors, especially marriage behaviors, generally differ from those in Western Germany (Kreyenfeld et al., 2016), therefore we control for the region a person lives in at the time of interview. Moreover, international immigrants might hold more traditional gender role attitudes. Thus, we control whether a person was born outside of Germany, which was the case for $9 \%$ of respondents in the total sample. 


\section{Analytical Strategy}

The aim of this study is to identify factors that are associated with whether a person moves or has the partner move in at the start of coresidence. Theoretically, we expect that the mechanism underlying the moving decision differs between long- and shortdistance moves. Therefore, we estimate separate models by distance. Unfortunately, the distance moved by the partners is not reported in pairfam. As a proxy, we rely on the information whether a couple has been living in a short-distance relationship (less than $1 \mathrm{~h}$ travel distance) or long-distance relationship (1 h or more travel distance) before coresidence started. We assume that a mover who had a long-distance relationship is more likely to move over a larger distance when starting coresidence. ${ }^{2}$ The vast majority of couples had a short-distance relationship $(n=736 ; 75 \%)$, while $25 \%(n=247)$ had a long-distance relationship before the start of coresidence.

In a first step, we discuss the descriptive statistics of the full sample, as well as the samples of long-distance and short-distance couples. Moreover, in additional analyses, we show the descriptive statistics by distance and gender (Table 3 in Appendix). In a second step, we estimate multiple logistic regressions to identify factors that are associated with moving versus having the partner move in. Again, we analyze short- and long-distance couples separately. In order to explore whether relative resources play out differently for men and women, we perform separate regressions for men and women (see Appendix).

One limitation of our study might be selectivity with regard to the speed of union formation. Those who were not in a relationship in wave $t-1$ but entered coresidence between two interviews were excluded from our main sample for lack of information about partner characteristics and distance in wave $t$ - 1 . In an additional analysis, we re-estimated our regression analyses including those couples who started both their relationship and coresidence since the last wave. This increased our sample size by 31 observations. The results of these additional analyses were very similar to the results we present and are therefore not shown. In other words, we did not find any indication that the duration of a LAT relationship affects the associations between the independent variables and the probability of moving at the start of coresidence.

\section{Descriptive Results}

Table 1 shows the descriptive statistics for the total sample as well as short- and longterm couples separately. We have also tested whether differences between short- and long-distance couples are statistically significant (see $p$-values in Table 1). The respondents in our sample are relatively young with a mean age of 27.4. In long-distance couples $(69.8 \%)$, anchors move more often than in short-distance couples $(62.8 \%)$. However, this difference is statistically insignificant. We find a significant difference

\footnotetext{
${ }^{2}$ In case that an anchor person, who reported a long-distance relationship in the last wave and had the partner move in at the start of coresidence, we can conclude that the partner moved over a long distance. However, it should be noted that in case that the anchor moved, it is possible that both partners move to a place that is geographically in between their two previous residences and thus one partner or both partners would fall into the "short-distance move" category. In such a case, our procedure leads to measurement error.
} 
between long- and short-distance couples for the variable anchor's travel time to parents. $54.9 \%$ of anchors in long-distance relationships live in close proximity to their parents (i.e., they have to travel less than $1 \mathrm{~h}$ to meet with their closest parent). Among those in short-distance relationships, the share that live close to their parents is considerably higher, at $80.5 \%$. One potential explanation for this finding might be that persons in long-distance relationships are generally more mobile and thus live farther away from their family than persons in short-distance relationships. Moreover, there is a marginally significant difference between long- and short-distance couples with regard to anchor's housing situation ( $p=0.089)$. In long-distance couples it is more common that the anchor lives in a crowded home than in short-distance couples. The other covariates do not differ significantly between short- and long-distance couples.

In Table 3 (see Appendix), we present additional descriptive analyses for men and women separately. Our results show that women have on average lower levels of relative resources than men. These differences are statistically significant.

\section{Multiple Regression Results}

In our main analyses, we estimated three logistic regression models of the anchor respondent's moving behavior at the start of coresidence. Model 1 in Table 2 presents the results for the full sample. Model 2 presents the regression results for the smaller sample of couples who were in a long-distance relationship before forming a joint household. Model 3 refers to couples in short-distance relationships before the move. In order to explore potential gender differences in the role of relative resources and local ties, we estimate separate regressions by gender. The results of these analyses are presented in Tables 4 and 5 in the Appendix.

We present average marginal effects (AME) and $p$-values. The average marginal effect is the mean of the marginal effects for each combination of covariates in the dataset. It represents the average change in the probability of seeing a specific outcome when we alter the respective independent variable from the reference to a different category based on our sample. In our models, the AME of a covariate can be interpreted as the change in the anchor person's probability of moving at the start of coresidence for the value of a variable compared to the reference category of this variable. While conclusions based on a direct comparison of odds ratios across different models can be erroneous, comparisons of AME are unproblematic (Mood, 2010). Because some of our sub-samples are small, we also discuss results with $p$-values between 0.05 and 0.10 .

In Model 1 in Table 2, the anchor's employment status, her/his housing situation and country of birth are significantly associated with the anchor's likelihood of relocation. For the partners' employment status, our results indicate that if an anchor person is employed full-time, while the partner's status is other, the anchor is less likely to move (AME $=-0.109, p=0.056$ ) than in cases where both partners are employed full-time (reference). With regard to the housing situation, we find that those who live with their parents have a $21.6 \%$ higher probability of moving $(p=0.001)$ compared to those who live in their own, uncrowded home (reference). Those living in their own crowded home also have an increased probability of moving $(\mathrm{AME}=0.161, p=0.004)$. Moreover, persons who are born outside Germany 
Table 2 Logistic regression analysis, outcome: anchor moves at the start of coresidence

\begin{tabular}{|c|c|c|c|c|c|c|}
\hline & \multicolumn{2}{|c|}{$\begin{array}{l}\text { Model } 1 \\
\text { Total sample }\end{array}$} & \multicolumn{2}{|c|}{$\begin{array}{l}\text { Model } 2 \\
\text { Subsample: long-distance } \\
\text { couples }\end{array}$} & \multicolumn{2}{|c|}{$\begin{array}{l}\text { Model } 3 \\
\text { Subsample: short- } \\
\text { distance couples }\end{array}$} \\
\hline & AME & $p$ value & AME & $p$ value & $\mathrm{AME}$ & $p$ value \\
\hline \multicolumn{7}{|l|}{ Distance to partner before move } \\
\hline Long distance $(1+\mathrm{h})$ & 0.036 & 0.395 & & & & \\
\hline Short distance $(<1 \mathrm{~h})$ & 0 & & & & & \\
\hline \multicolumn{7}{|l|}{ Gender of anchor } \\
\hline Male & 0 & & 0 & & 0 & \\
\hline Female & -0.070 & 0.134 & -0.047 & 0.567 & -0.068 & 0.216 \\
\hline Age of anchor person & -0.006 & 0.496 & -0.001 & 0.972 & -0.005 & 0.635 \\
\hline \multicolumn{7}{|l|}{ Age difference } \\
\hline Same age & 0 & & 0 & & 0 & \\
\hline Anchor older & -0.040 & 0.443 & 0.049 & 0.622 & -0.075 & 0.219 \\
\hline Anchor younger & 0.073 & 0.107 & 0.103 & 0.171 & 0.072 & 0.176 \\
\hline \multicolumn{7}{|l|}{ Educational difference } \\
\hline Same education & 0 & & 0 & & 0 & \\
\hline Anchor higher & -0.078 & 0.154 & -0.267 & 0.004 & -0.023 & 0.716 \\
\hline Anchor lower & 0.029 & 0.566 & 0.056 & 0.563 & 0.016 & 0.784 \\
\hline \multicolumn{7}{|l|}{ Difference in employment status } \\
\hline Both full-time & 0 & & 0 & & 0 & \\
\hline Both other & -0.075 & 0.179 & -0.095 & 0.422 & -0.059 & 0.374 \\
\hline Anchor full-time, partner other & -0.109 & 0.056 & -0.116 & 0.235 & -0.118 & 0.096 \\
\hline Partner full-time, anchor other & -0.066 & 0.267 & 0.032 & 0.782 & -0.104 & 0.136 \\
\hline \multicolumn{7}{|l|}{ Children of anchor } \\
\hline No children & 0 & & 0 & & 0 & \\
\hline 1 or more children & -0.085 & 0.279 & -0.137 & 0.302 & -0.076 & 0.403 \\
\hline \multicolumn{7}{|l|}{ Anchor's travel time to parent(s) } \\
\hline Long distance $(1+\mathrm{h})$ & 0 & & 0 & & 0 & \\
\hline Short distance $(<1 \mathrm{~h})$ & -0.093 & 0.118 & -0.115 & 0.221 & -0.099 & 0.141 \\
\hline \multicolumn{7}{|l|}{ Anchor's housing situation } \\
\hline Lives with parents & 0.216 & 0.001 & -0.033 & 0.717 & 0.282 & 0.000 \\
\hline Own household: crowded & 0.160 & 0.004 & -0.081 & 0.282 & 0.225 & 0.000 \\
\hline Own household: uncrowded & 0 & & 0 & & 0 & \\
\hline \multicolumn{7}{|l|}{ Birth cohort (anchor) } \\
\hline $1991-1993$ & 0 & & 0 & & 0 & \\
\hline $1981-1983$ & -0.017 & 0.827 & -0.121 & 0.363 & 0.010 & 0.912 \\
\hline $1971-1973$ & 0.021 & 0.896 & -0.190 & 0.567 & 0.045 & 0.816 \\
\hline \multicolumn{7}{|l|}{ Region (anchor) } \\
\hline Western Germany & 0 & & 0 & & 0 & \\
\hline Eastern Germany & 0.062 & 0.176 & 0.046 & 0.531 & 0.070 & 0.197 \\
\hline \multicolumn{7}{|l|}{ Country of birth (anchor) } \\
\hline Germany & 0 & & 0 & & 0 & \\
\hline Other & -0.143 & 0.086 & -0.058 & 0.667 & -0.181 & 0.067 \\
\hline Number of partnerships & 983 & & 247 & & 736 & \\
\hline
\end{tabular}


Table 2 (continued)

Average marginal effects

The anchor is the main respondent in the multi-actor design of pairfam. Short-distance couples are those who had to travel less than $1 \mathrm{~h}$ to meet the partner before coresidence. Long-distance couples are those who had to travel $1 \mathrm{~h}$ or more. Source: pairfam, waves 1-10 (2008/2009-2017/2018). Weighted data (for details of the weighting procedure, see pairfam Group 2020)

are less likely to move at the start of coresidence (AME $=-0.143, p=0.086)$ than those born in Germany (reference). In Model 1, we also controlled for the distance between partners before the move. However, the effect is small and insignificant.

Model 2 presents the results for the sample of long-distance couples. Only one variant of the relative resources is statistically significant in this model: the educational difference between partners. In couples where the anchor has higher education than the partner, the anchor is less likely to move (AME $=-0.267, p=0.004$ ) than in couples with the same educational level (reference). We do not find evidence for our hypothesis 2 a that social ties are associated with a lower probability of moving: the coefficients of the variables Children of anchor and Anchor's travel time to parent( $(s)$ are small with large $p$-values. The other coefficients in this model are also rather small and statistically insignificant.

With regard to short-distance couples (Model 3), they seem to drive the results found in Model 1. Theoretically, for short-distance moves we expected that a person's housing situation would be especially important in making relocation decisions. In line with Hypotheses $1 \mathrm{a}$ and $1 \mathrm{~b}$, persons who live in their parents' home and those who live in their own crowded home are more likely to move than those who live in their own uncrowded home. Moreover, we find that an employment situation with an anchor employed full-time and a partner with other employment status is associated with a lower probability of moving ( $\mathrm{AME}=-0.118, p=0.096$ ) compared to couples where both partners are employed full-time (reference). Theoretically, we did not expect such differences by relative resources in short-distance couples. With regard to the other control variables, we found that anchors born outside Germany are less likely to move than German-born persons. This might indicate that local social networks are more relevant for immigrants than for natives.

In our third hypothesis, we expected that women are more likely to move than men at the start of coresidence. We do not find evidence for this in Models 1, 2 and 3. Also in a bivariate analysis (result not shown), gender was not significantly associated with the probability of moving. In order to explore how relative resources (and other couple characteristics) affect men and women differently, we performed additional analyses by gender. Table 4 in the Appendix shows two interesting gender differences. First, women who are younger than their partner have an increased probability of moving $(\mathrm{AME}=0.093, p=0.076)$ relative to those who are the same age as their partners (reference). This effect is not found among men. Second, women who live in close proximity to at least one of their parents are less likely to move (AME $=-0.151, p=0.006)$ than those who do not live close to their parents (reference). This pattern persists for women in long- and short-distance couples (Table 5 in Appendix), while it does not appear for men. The analyses by gender and distance also reveal additional differences between subgroups. For example, women from the early 1970s and early 1980s birth cohorts were significantly less likely to move than those from the early 1990s cohort. However, 
it should be noted that the case numbers in the smaller sample of long-distance relationships are quite small in some of the categories, e.g., $n=28$ women belong to the 1970 s cohort and $n=24$ women lived in their own uncrowded home. Therefore, we refrain from drawing strong conclusions about these gender differences.

\section{Discussion}

In this study, we analyzed couples' decisions about who moves and who stays in their home at the start of coresidence. Our findings showed differences in the conditions associated with relocation depending on partners' travel distance before the formation of a joint household. For short-distance couples, the housing situation seemed to be relevant for the moving decision. Persons who live with their parents as well as those who have their own crowded home were more likely to move than those who live in their own uncrowded home. This supports our hypotheses $1 \mathrm{a}$ and $1 \mathrm{~b}$ and indicates that household formation in the context of a short-distance move is a practical reaction to new space demands, as has been suggested for family moves, e.g., in the period around the birth of a child (Rossi, 1955). Moreover, our findings add to the emerging literature on the relevance of the housing situation for partnership development and moving decisions (Coulter \& Thomas, 2019; Krapf \& Wagner, 2020; van Damme et al., 2018). Moreover, we found that relative resources were relevant for the decision to relocate in short-distance couples as well. Respondents who were employed full-time and had a partner who was in the other employment category were less likely to move than respondents in a couple with two partners employed full-time.

In long-distance couples, our findings also partly support the hypotheses that relative resources (and family ties for women) matter in determining who moves at the start of coresidence. Respondents with higher educational attainment than their partner are less likely to move than those with the same educational level. This was the case for both men and women. For women, we found that those who are younger than their partner had an increased probability of moving than those with the same age. By contrast, we did not find evidence for an effect of relative resources with regard to employment status. This pattern might indicate the central role of partners' earning potential (that is associated with their education) in the decision to move over a long distance.

We did not find a strong main effect of gender on the probability of moving at the start of coresidence. However, in separate analyses we found that the factors that are associated with moving seemed to differ between men and women. Women in longand short-distance relationships who live in close proximity to at least one of their parents had a lower probability of moving than those who live further away from their parents. For men, this effect was not found. One reason for this might be that daughters provide care for their parents more frequently than sons (Leopold et al., 2014). Providing support to parents (or anticipating the need to provide care in the future) might keep women from moving away from the place where their parents live.

Prior research finds that women are more likely to move compared to men at the start of coresidence in Sweden (Brandén \& Haandrikman, 2019) and in other studies about gendered moving patterns within families (Fan \& Huang, 1998) (although differences were not very large). Moreover, in Germany family migration seems to be driven 
more by the man's employment and position than the woman's (Vidal et al., 2017). We therefore expected that moving at the start of coresidence would also be more likely among women than men in Germany. However, in our data, we do not find a strong gender difference in the probability to move. Women who live close to their parents were even less likely to move-which contradicts the gender hypothesis. These findings might be associated with our focus on partnership behaviors among young individuals, with a mean age of 27 years in our sample. Brandén and Haandrikman (2019) analyzed a sample consisting exclusively of couples that later married or had a child. Gendered attitudes and behaviors often become more traditional after a child is born (Baxter et al., 2015; Endendijk et al., 2018). This might also extend to the moving decision. Indeed, it has been shown that gendered patterns in family migration occur for mothers, but not for childless women (Cooke, 2001). Therefore, our findings might be evidence of egalitarian moving behaviors among young couples. Apart from the insignificant main effect of gender, we did find differences associated with relative resources for men and women in short-distance relationships - which we actually expected to find for persons in long-distance relationships. However, we acknowledge that our findings have to be interpreted with caution because the sample sizes in some categories were quite small.

Given the few existing studies on the topic, we need more research about moving at the start of coresidence. First of all, we need larger datasets to enlarge statistical power when assessing moving decisions in sub-categories, i.e., for long- versus short-distance moves and among men versus women. Moreover, we only had information about whether the respondent moved or not but we were unable to distinguish between those couples in which the respondent moved in with the partner or both moved to a new home. This limitation in the measurement of our outcome variable might lead to a biased estimation of the role of relative resources in the moving decision. To illustrate this point, we compare two hypothetical couples, one with similar relative resources, and one where the partner has more resources than the anchor. Following from the bargaining approach, partners with similar relative resources would agree to move to a new place as a reasonable compromise. By contrast, in the couple where the partner has more resources than the anchor, the anchor moves to the partner's place. With our data, we group both cases together into the "anchor moves"-category, which might obscure part of the measured effect of relative resources. Another data limitation is related to the measurement of distance moved. This information is not collected for the partner in the pairfam survey. Instead, we used the distance between the partners before they established a joint household. If the couple was in a long-distance relationship, it is possible that both partners moved to a place that is geographically between their two previous residences and potentially one or both partners would move a short distance. In this example, our procedure leads to measurement error. In order to avoid such measurement problems, in future surveys more data from LAT partners should be collected.

\section{Appendix}

See Tables 3, 4 and 5. 
Table 3 Descriptive statistics by gender and $p$-values

\begin{tabular}{|c|c|c|c|c|c|c|}
\hline & \multicolumn{3}{|c|}{ Long-distance couples } & \multicolumn{3}{|c|}{ Short-distance couples } \\
\hline & Men & Women & $p$ value & Men & Women & $p$ value \\
\hline \multicolumn{7}{|l|}{ Outcome variable: anchor moves } \\
\hline Yes & 65.5 & 73.3 & & 63.1 & 62.8 & \\
\hline No & 34.5 & 26.7 & 0.287 & 36.9 & 37.4 & 0.924 \\
\hline Age of anchor person & 28.9 & 26.0 & 0.002 & 28.9 & 26.4 & 0.002 \\
\hline \multicolumn{7}{|l|}{ Age difference } \\
\hline Same age & 32.1 & 48.8 & & 39.4 & 38.1 & \\
\hline Anchor older & 48.8 & 5.1 & & 48.3 & 11.2 & \\
\hline Anchor younger & 19.1 & 46.1 & 0.000 & 12.4 & 50.7 & 0.000 \\
\hline \multicolumn{7}{|l|}{ Educational difference } \\
\hline Same education & 58.9 & 50.6 & & 59.2 & 59.6 & \\
\hline Anchor higher & 27.7 & 19.6 & & 27.8 & 15.7 & \\
\hline Anchor lower & 13.5 & 29.8 & 0.059 & 13.1 & 24.7 & 0.015 \\
\hline \multicolumn{7}{|l|}{ Difference in employment status } \\
\hline Both full-time & 31.2 & 28.0 & & 38.7 & 34.4 & \\
\hline Both other & 24.4 & 30.1 & & 28.2 & 27.5 & \\
\hline Anchor full-time, partner other & 34.1 & 11.0 & & 27.0 & 6.3 & \\
\hline Partner full-time, anchor other & 10.3 & 30.9 & 0.001 & 6.2 & 31.9 & 0.000 \\
\hline \multicolumn{7}{|l|}{ Children of anchor } \\
\hline No children & 96.3 & 90.8 & & 86.6 & 88.6 & \\
\hline 1 or more children & 3.7 & 9.2 & 0.073 & 13.4 & 11.4 & 0.573 \\
\hline \multicolumn{7}{|l|}{ Anchor's travel time to parents } \\
\hline Long distance $(1+\mathrm{h})$ & 32.7 & 55.2 & & 18.8 & 20.1 & \\
\hline Short distance $(<1 \mathrm{~h})$ & 67.3 & 44.8 & 0.007 & 81.2 & 80.0 & 0.758 \\
\hline \multicolumn{7}{|l|}{ Anchor's housing situation } \\
\hline Lives with parents & 25.6 & 24.3 & & 32.1 & 26.3 & \\
\hline Own household: crowded & 53.1 & 62.0 & & 43.5 & 51.8 & \\
\hline Own household: uncrowded & 21.2 & 13.7 & 0.359 & 24.4 & 21.9 & 0.086 \\
\hline \multicolumn{7}{|l|}{ Birth cohort (anchor) } \\
\hline $1991-1993$ & 32.9 & 59.4 & & 36.2 & 54.4 & \\
\hline $1981-1983$ & 50.1 & 32.2 & & 45.4 & 35.0 & \\
\hline $1971-1973$ & 17.1 & 8.4 & 0.002 & 18.4 & 10.6 & 0.002 \\
\hline \multicolumn{7}{|l|}{ Region (anchor) } \\
\hline Western Germany & 86.7 & 83.6 & & 86.3 & 84.1 & \\
\hline Eastern Germany & 13.3 & 16.4 & 0.547 & 13.7 & 15.9 & 0.481 \\
\hline \multicolumn{7}{|l|}{ Country of birth (anchor) } \\
\hline Germany & 87.8 & 92.5 & & 93.7 & 89.7 & \\
\hline Other & 12.2 & 7.5 & 0.320 & 6.4 & 10.3 & 0.416 \\
\hline Number of partnerships & 111 & 136 & & 314 & 422 & \\
\hline
\end{tabular}

Column percentage or means

The anchor is the main respondent within the multi-actor design of pairfam. Short-distance couples are those who had to travel less than $1 \mathrm{~h}$ to meet the partner before coresidence. Long-distance couples are those who had to travel $1 \mathrm{~h}$ or more. Percentages may not sum to 100 due to rounding. Source: pairfam, waves 1-10 (2008/2009-2017/2018). Weighted data (for details of the weighting procedure, see pairfam Group 2020). $p$-values refer to the adjusted Wald test (test of independence with weighted data), comparison of men and women 
Table 4 Logistic regression analysis by gender, outcome: anchor moves at the start of coresidence

\begin{tabular}{|c|c|c|c|c|}
\hline & \multicolumn{4}{|c|}{ All couples } \\
\hline & \multicolumn{2}{|l|}{ Men } & \multicolumn{2}{|l|}{ Women } \\
\hline & AME & $p$ value & AME & $p$ value \\
\hline \multicolumn{5}{|l|}{ Distance to partner before move } \\
\hline Long distance $(1+\mathrm{h})$ & 0.015 & 0.807 & 0.031 & 0.583 \\
\hline Short distance $(<1 \mathrm{~h})$ & 0 & & 0 & \\
\hline Age of anchor person & -0.012 & 0.412 & 0.003 & 0.784 \\
\hline \multicolumn{5}{|l|}{ Age difference } \\
\hline Same age & 0 & & 0 & \\
\hline Anchor older & -0.045 & 0.482 & -0.153 & 0.141 \\
\hline Anchor younger & -0.045 & 0.605 & 0.093 & 0.076 \\
\hline \multicolumn{5}{|l|}{ Educational difference } \\
\hline Same education & 0 & & 0 & \\
\hline Anchor higher & -0.109 & 0.127 & -0.016 & 0.843 \\
\hline Anchor lower & 0.015 & 0.863 & 0.033 & 0.547 \\
\hline \multicolumn{5}{|l|}{ Difference in employment status } \\
\hline Both full-time & 0 & & 0 & \\
\hline Both other & 0.032 & 0.691 & -0.136 & 0.057 \\
\hline Anchor full-time, partner other & -0.127 & 0.098 & -0.049 & 0.557 \\
\hline Partner full-time, anchor other & -0.052 & 0.661 & -0.098 & 0.126 \\
\hline \multicolumn{5}{|l|}{ Children of anchor } \\
\hline No children & 0 & & 0 & \\
\hline 1 or more children & -0.145 & 0.240 & 0.025 & 0.724 \\
\hline \multicolumn{5}{|l|}{ Anchor's travel time to parents } \\
\hline Long distance $(1+\mathrm{h})$ & 0 & & 0 & \\
\hline Short distance $(<1 \mathrm{~h})$ & -0.087 & 0.243 & -0.151 & 0.006 \\
\hline \multicolumn{5}{|l|}{ Anchor's housing situation } \\
\hline Lives with parents & 0.162 & 0.074 & 0.263 & 0.001 \\
\hline Own household: crowded & 0.161 & 0.047 & 0.156 & 0.032 \\
\hline Own household: uncrowded & 0 & & 0 & \\
\hline \multicolumn{5}{|l|}{ Birth cohort (anchor) } \\
\hline $1991-1993$ & 0 & & 0 & \\
\hline $1981-1983$ & 0.144 & 0.161 & -0.189 & 0.055 \\
\hline $1971-1973$ & 0.185 & 0.398 & -0.198 & 0.379 \\
\hline \multicolumn{5}{|l|}{ Region (anchor) } \\
\hline Western Germany & 0 & & 0 & \\
\hline Eastern Germany & 0.091 & 0.185 & 0.043 & 0.476 \\
\hline \multicolumn{5}{|l|}{ Country of birth (anchor) } \\
\hline Germany & 0 & & 0 & \\
\hline Other & -0.160 & 0.211 & -0.087 & 0.346 \\
\hline Number of partnerships & 425 & & 558 & \\
\hline
\end{tabular}

\section{Average marginal effects}

The anchor is the main respondent in the multi-actor design of pairfam. Short-distance couples are those who had to travel less than $1 \mathrm{~h}$ to meet the partner before coresidence. Long-distance couples are those who had to travel $1 \mathrm{~h}$ or more. Source: pairfam, waves 1-10 (2008/2009-2017/2018). Weighted data (for details of the weighting procedure, see pairfam Group 2020) 
Table 5 Logistic regression analysis by distance and gender, outcome: anchor moves at the start of coresidence

\begin{tabular}{|c|c|c|c|c|c|c|c|c|}
\hline & \multicolumn{4}{|c|}{ Long-distance couples } & \multicolumn{4}{|c|}{ Short-distance couples } \\
\hline & \multicolumn{2}{|l|}{ Men } & \multicolumn{2}{|l|}{ Women } & \multicolumn{2}{|l|}{ Men } & \multicolumn{2}{|l|}{ Women } \\
\hline & AME & $p$ value & AME & $p$ value & AME & $p$ value & AME & $p$ value \\
\hline Age of anchor & -0.032 & 0.169 & 0.027 & 0.286 & -0.007 & 0.641 & 0.005 & 0.715 \\
\hline \multicolumn{9}{|l|}{ Age difference } \\
\hline Same age & 0 & & 0 & & 0 & & 0 & \\
\hline Anchor older & 0.106 & 0.285 & -0.013 & 0.941 & -0.111 & 0.122 & -0.161 & 0.164 \\
\hline Anchor younger & 0.108 & 0.447 & 0.111 & 0.172 & -0.089 & 0.372 & 0.099 & 0.112 \\
\hline \multicolumn{9}{|l|}{ Educational difference } \\
\hline Same education & 0 & & 0 & & 0 & & 0 & \\
\hline Anchor higher & -0.272 & 0.017 & -0.281 & 0.063 & -0.028 & 0.726 & 0.042 & 0.630 \\
\hline Anchor lower & 0.170 & 0.194 & -0.058 & 0.590 & -0.037 & 0.710 & 0.045 & 0.477 \\
\hline \multicolumn{9}{|l|}{ Difference in employment status } \\
\hline Both full-time & 0 & & 0 & & 0 & & 0 & \\
\hline Both other & -0.151 & 0.283 & -0.013 & 0.941 & 0.114 & 0.203 & -0.154 & 0.061 \\
\hline Anchor full-time, partner other & -0.199 & 0.084 & 0.004 & 0.984 & -0.129 & 0.160 & -0.065 & 0.552 \\
\hline Partner full-time, anchor other & 0.118 & 0.386 & 0.087 & 0.601 & -0.167 & 0.217 & -0.133 & 0.068 \\
\hline \multicolumn{9}{|l|}{ Children of anchor } \\
\hline No children & 0 & & 0 & & 0 & & 0 & \\
\hline 1 or more children & 0.015 & 0.934 & -0.135 & 0.518 & -0.161 & 0.224 & 0.046 & 0.559 \\
\hline \multicolumn{9}{|l|}{ Anchor's travel time to parent(s) } \\
\hline Long distance $(1+\mathrm{h})$ & 0 & & 0 & & 0 & & 0 & \\
\hline Short distance $(<1 \mathrm{~h})$ & -0.114 & 0.178 & -0.180 & 0.084 & -0.100 & 0.315 & -0.145 & 0.031 \\
\hline \multicolumn{9}{|l|}{ Anchor's housing situation } \\
\hline Lives with parents & 0.025 & 0.853 & -0.045 & 0.698 & 0.225 & 0.043 & 0.328 & 0.000 \\
\hline Own household: crowded & 0.088 & 0.412 & -0.193 & 0.036 & 0.187 & 0.055 & 0.239 & 0.004 \\
\hline Own household: uncrowded & 0 & & 0 & & 0 & & 0 & \\
\hline \multicolumn{9}{|l|}{ Birth cohort (anchor) } \\
\hline 1991-1993 & 0 & & 0 & & 0 & & 0 & \\
\hline $1981-1983$ & 0.128 & 0.443 & -0.403 & 0.003 & 0.194 & 0.066 & -0.193 & 0.096 \\
\hline $1971-1973$ & 0.350 & 0.165 & -0.656 & 0.004 & 0.181 & 0.467 & -0.196 & 0.469 \\
\hline \multicolumn{9}{|l|}{ Region (anchor) } \\
\hline Western Germany & 0 & & 0 & & 0 & & 0 & \\
\hline Eastern Germany & 0.001 & 0.991 & 0.132 & 0.131 & 0.128 & 0.109 & 0.036 & 0.606 \\
\hline \multicolumn{9}{|l|}{ Country of birth (anchor) } \\
\hline Germany & 0 & & 0 & & 0 & & 0 & \\
\hline Other & -0.261 & 0.088 & 0.150 & 0.087 & -0.067 & 0.598 & -0.186 & 0.104 \\
\hline Number of partnerships & 112 & & 135 & & 313 & & 423 & \\
\hline
\end{tabular}

Average marginal effects

The anchor is the main respondent in the multi-actor design of pairfam. Short-distance couples are those who had to travel less than $1 \mathrm{~h}$ to meet the partner before coresidence. Long-distance couples are those who had to travel $1 \mathrm{~h}$ or more. Source: pairfam, waves 1-10 (2008/2009-2017/2018). Weighted data (for details of the weighting procedure, see pairfam Group 2020) 
Acknowledgements This paper uses data from the German Family Panel pairfam, coordinated by Josef Brüderl, Sonja Drobnič, Karsten Hank, Bernhard Nauck, Franz Neyer und Sabine Walper. Pairfam is funded as a long-term project by the German Research Foundation (DFG).

Funding Open Access funding enabled and organized by Projekt DEAL. The research for this paper is part of the project "Partner relationships, residential relocations and housing in the life course" (PartnerLife). Principal investigators: Clara H. Mulder (University of Groningen), Michael Wagner (University of Cologne), and Hill Kulu (University of Liverpool). PartnerLife is supported by a grant from the Netherlands Organisation for Scientific Research (NWO, Grant No. 464-13-148), the Deutsche ForschungsGemeinschaft (DFG, Grant No. WA1502/6-1), and the Economic and Social Research Council (ESRC, Grant No. ES/L01663X/1) in the Open Research Area Plus scheme. Clara Mulder's contribution is also part of the FamilyTies project. The FamilyTies project has received funding from the European Research Council (ERC) under the European Union's Horizon 2020 research and innovation programme (Grant Agreement No 740113).

Open Access This article is licensed under a Creative Commons Attribution 4.0 International License, which permits use, sharing, adaptation, distribution and reproduction in any medium or format, as long as you give appropriate credit to the original author(s) and the source, provide a link to the Creative Commons licence, and indicate if changes were made. The images or other third party material in this article are included in the article's Creative Commons licence, unless indicated otherwise in a credit line to the material. If material is not included in the article's Creative Commons licence and your intended use is not permitted by statutory regulation or exceeds the permitted use, you will need to obtain permission directly from the copyright holder. To view a copy of this licence, visit http://creativecommons.org/licen ses/by/4.0/.

\section{References}

Aboim, S. (2010). Gender cultures and the division of labour in contemporary Europe: A cross-national perspective. Sociological Review, 58(2), 171-196. https://doi.org/10.1111/j.1467-954X.2010. 01899.x

Abraham, M., Auspurg, K., \& Hinz, T. (2010). Migration decisions within dual-earner partnerships: A test of Bargaining Theory. Journal of Marriage and Family, 72(4), 876-892. https://doi.org/10. 1111/j.1741-3737.2010.00736.x

Angelini, V., Laferrère, A., \& Weber, G. (2013). Home-ownership in Europe: How did it happen? Advances in Life Course Research, 18(1), 83-90. https://doi.org/10.1016/j.alcr.2012.10.006

Baxter, J., Buchler, S., Perales, F., \& Western, M. (2015). A life-changing event: First births and men's and women's attitudes to mothering and gender divisions of labor. Social Forces, 93(3), 989-1014. https://doi.org/10.1093/sf/sou103

Bayrakdar, S., Coulter, R., Lersch, P., \& Vidal, S. (2019). Family formation, parental background and young adults' first entry into homeownership in Britain and Germany. Housing Studies, 34(6), 974996. https://doi.org/10.1080/02673037.2018.1509949

Bielby, W. T., \& Bielby, D. D. (1992). I will follow him: Family ties, gender-role beliefs, and reluctance to relocate for a better job. American Journal of Sociology, 97(5), 1241-1267. https://doi.org/10. 1086/229901

Blaauboer, M., Mulder, C. H., \& Zorlu, A. (2011). Distances between couples and the man's and woman's parents. Population, Space and Place, 17(5), 597-610. https://doi.org/10.1002/psp.648

Brandén, M., \& Haandrikman, K. (2019). Who moves to whom? Gender differences in the distance moved to a shared residence. European Journal of Population, 35(3), 435-458. https://doi.org/10. 1007/s10680-018-9490-4

Brüderl, J., Drobnič, S., Hank, K., Nauck, B., Neyer, F. J., Walper, S., et al. (2019a). The German family panel (pairfam). GESIS Data Archive, Cologne, ZA5678 Data file Version 10.0.0. https://doi.org/ 10.4232/pairfam.5678.10.0.0

Brüderl, J., Hajek, K., Herzig, M., Lenke, R., Müller, B., \& Schütze, P. (2019b). pairfam Data Manual. Release 10.0. Technical report. LMU. 
Brüderl, J., Schmiedeberg, C., Castiglioni, L., Arránz Becker, O., Petra Buhr, Fuß, D., et al. (2020). The German family panel: Study design and cumulated field report (waves 1 to 11). Release 11.0. pairfam Technical paper. München.

Clark, W. A. V., \& Huang, Y. Q. (2004). Linking migration and mobility: Individual and contextual effects in housing markets in the UK. Regional Studies, 38(6), 617-628. https://doi.org/10.1080/ 003434042000240932

Coley, R. L., \& Kull, M. (2016). Cumulative, timing-specific, and interactive models of residential mobility and children's cognitive and psychosocial skills. Child Development, 87(4), 1204-1220. https:// doi.org/10.1111/cdev.12535

Cooke, T. J. (2001). 'Trailing wife' or 'trailing mother'? The effect of parental status on the relationship between family migration and the labor-market participation of married women. Environment and Planning a: Economy and Space, 33(3), 419-430. https://doi.org/10.1068/a33140

Cooke, T. J. (2008a). Gender role beliefs and family migration. Population, Space and Place, 14(3), 163175. https://doi.org/10.1002/psp.485

Cooke, T. J. (2008b). Migration in a family way. Population Space and Place, 14(4), 255-265. https://doi. org/10.1002/psp. 500

Cooke, T. J., Mulder, C. H., \& Thomas, M. (2016). Union dissolution and migration. Demographic Research, 34(26), 741-760. https://doi.org/10.4054/DemRes.2016.34.26

Coulter, R., \& Thomas, M. (2019). A new look at the housing antecedents of separation. Demographic Research, 40(26), 725-760.

DaVanzo, J. (1981). Repeat migration, information costs, and location-specific capital. Population and Environment, 4(1), 45-73. https://doi.org/10.1007/bf01362575

Dommermuth, L., \& Klüsener, S. (2019). Formation and realisation of moving intentions across the adult life course. Population, Space and Place, 25(5), e2212. https://doi.org/10.1002/psp.2212

Duncan, S., \& Phillips, M. (2010). People who live apart together (LATs)—How different are they? The Sociological Review, 58(1), 112-134. https://doi.org/10.1111/j.1467-954X.2009.01874.x

Endendijk, J. J., Derks, B., \& Mesman, J. (2018). Does parenthood change implicit gender-role stereotypes and behaviors? Journal of Marriage and Family, 80(1), 61-79. https://doi.org/10.1111/jomf. 12451

Ermisch, J., \& Mulder, C. H. (2019). Migration versus immobility, and ties to parents. European Journal of Population, 35(3), 587-608.

Eurostat. (2020). Distribution of population by tenure status, type of household and income group-EUSILC survey [ilc_lvho02]. Retrieved December 14, 2020, from http://appsso.eurostat.ec.europa.eu/ nui/show.do?wai=true\&dataset=ilc_lvho02

Fan, C. C., \& Huang, Y. (1998). Waves of rural brides: Female marriage migration in China. Annals of the Association of American Geographers, 88(2), 227-251.

Feijten, P. (2005). Union dissolution, unemployment and moving out of homeownership. European Sociological Review, 21(1), 59-71. https://doi.org/10.1093/esr/jci004

Fischer, P. A., \& Malmberg, G. (2001). Settled people don't move: On life course and (im-)mobility in Sweden. International Journal of Population Geography, 7(5), 357-371. https://doi.org/10.1002/ ijpg.230

Huinink, J., Brüderl, J., Nauck, B., Walper, S., Castiglioni, L., \& Feldhaus, M. (2011). Panel analysis of intimate relationships and family dynamics (pairfam): Conceptual framework and design. Zeitschrift Für Familienforschung, 23(1), 77-101.

Hünteler, B., \& Mulder, C. H. (2020). Geographic proximity to parents, intergenerational support exchange, and migration within Germany. European Journal of Population, 36(5), 895-918. https:// doi.org/10.1007/s10680-020-09558-w

Kiernan, K. (2001). The rise of cohabitation and childbearing outside marriage in western Europe. International Journal of Law, Policy and the Family, 15(1), 1-21. https://doi.org/10.1093/lawfam/15.1.1

Konietzka, D., \& Tatjes, A. (2014). Two steps of union formation: First intimate relationships and first coresidential unions in the life courses of the German Cohorts 1971-1973 and 1981-1983. Journal of Youth Studies, 17(8), 1077-1096. https://doi.org/10.1080/13676261.2014.888405

Krapf, S. (2018). Moving in or breaking up? The role of distance in the development of romantic relationships. European Journal of Population, 34(3), 313-336. https://doi.org/10.1007/s10680-017-9428-2

Krapf, S., \& Wagner, M. (2020). Housing affordability, housing tenure status and household density: Are housing characteristics associated with union dissolution? European Journal of Population. https:// doi.org/10.1007/s10680-019-09549-6 
Kreyenfeld, M., Konietzka, D., \& Heintz-Martin, V. (2016). Private Lebensformen in Ost- und Westdeutschland. In Y. Niephaus, M. Kreyenfeld, \& R. Sackmann (Eds.), Handbuch Bevölkerungssoziologie (pp. 303-325). Springer Fachmedien Wiesbaden.

Kulu, H., \& Steele, F. (2013). Interrelationships between childbearing and housing transitions in the family life course. Demography, 50(5), 1687-1714. https://doi.org/10.1007/s13524-013-0216-2

Lennartz, C., \& Helbrecht, I. (2018). The housing careers of younger adults and intergenerational support in Germany's 'society of renters.' Housing Studies, 33(2), 317-336. https://doi.org/10.1080/02673 037.2017.1338674

Leopold, T., Raab, M., \& Engelhardt, H. (2014). The transition to parent care: Costs, commitments, and caregiver selection among children. Journal of Marriage and Family, 76(2), 300-318. https://doi. org/10.1111/jomf.12099

Lersch, P. M., \& Vidal, S. (2014). Falling out of love and down the housing ladder: A longitudinal analysis of marital separation and home ownership. European Sociological Review, 30(4), 512-524. https://doi.org/10.1093/esr/jcu055

Liefbroer, A. C., Poortman, A.-R., \& Seltzer, J. (2015). Why do intimate partners live apart? Evidence on LAT relationships across Europe. Demographic Research, 32(8), 251-286.

Løken, K. V., Lommerud, K. E., \& Lundberg, S. (2013). Your place or mine? On the residence choice of young couples in Norway. Demography, 50(1), 285-310. https://doi.org/10.1007/ s13524-012-0142-8

Lundberg, S., \& Pollak, R. A. (1996). Bargaining and distribution in marriage. The Journal of Economic Perspectives, 10(4), 139-158.

Mikolai, J. (2017). Partnership histories and the transition to motherhood in later reproductive ages in Europe. Population, 72(1), 127-158. https://doi.org/10.3917/popu.1701.0127

Mikolai, J., \& Kulu, H. (2018). Divorce, separation, and housing changes: A multiprocess analysis of longitudinal data from England and Wales. Demography, 55(1), 83-106. https://doi.org/10.1007/ s13524-017-0640-9

Mincer, J. (1978). Family migration decisions. Journal of Political Economy, 86(5), 749-773.

Mood, C. (2010). Logistic regression: Why we cannot do what we think we can do, and what we can do about it. European Sociological Review, 26(1), 67-82. https://doi.org/10.1093/esr/jcp006

Mortelmans, D., Pasteels, I., Regnier-Loilier, A., Vignoli, D., \& Mazzuco, S. (2015). Analysis of determinants and prevalence of LAT. FamiliesAndSocieties Working Paper Series 25(2015).

Mulder, C. H., \& Malmberg, G. (2014). Local ties and family migration. Environment and Planning a: Economy and Space, 46(9), 2195-2211.

Mulder, C. H., \& Wagner, M. (1993). Migration and marriage in the life course: A method for studying synchronized events. European Journal of Population, 9(1), 55-76.

Mulder, C. H., \& Wagner, M. (2012). Moving after separation: The role of location-specific capital. Housing Studies, 27(6), 839-852. https://doi.org/10.1080/02673037.2012.651109

Müller, B., \& Castiglioni, L. (2020). Do temporary dropouts improve the composition of panel data? An analysis of "gap interviews" in the German family panel pairfam. Sociological Methods \& Research, 49(1), 193-215. https://doi.org/10.1177/0049124117729710

Niedomysl, T., \& Fransson, U. (2014). On distance and the spatial dimension in the definition of internal migration. Annals of the Association of American Geographers, 104(2), 357-372. https://doi.org/10. 1080/00045608.2013.875809

Oishi, S. (2010). The psychology of residential mobility: Implications for the self, social relationships, and well-being. Perspectives on Psychological Science, 5(1), 5-21. https://doi.org/10.1177/17456 91609356781

Oswald, F. (2019). The effect of homeownership on the option value of regional migration. Quantitative Economics, 10(4), 1453-1493. https://doi.org/10.3982/qe872

Pairfam Group. (2020). Quick Start Syntax Weighting, Release 11.0. GESIS Data Archive, Cologne. ZA5678 Data File Version 11.0. https://www.pairfam.de/fileadmin/user_upload/redakteur/publis/ Dokumentation/SyntaxFiles/Release_11.0/Quick\%20Start\%20Weighting.do

Régnier-Loilier, A. (2016). Partnership trajectories of people in stable non-cohabiting relationships in France. Demographic Research, 35(40), 1169-1212.

Rossi, P. H. (1955). Why families move: A study in the social psychology of urban residential mobility. Free Press.

Sassler, S., Michelmore, K., \& Holland, J. A. (2016). The progression of sexual relationships. Journal of Marriage and Family, 78(3), 587-597. https://doi.org/10.1111/jomf.12289 
Scarborough, W. J., Sin, R., \& Risman, B. (2019). Attitudes and the stalled gender revolution: Egalitarianism, traditionalism, and ambivalence from 1977 through 2016. Gender \& Society, 33(2), 173200. https://doi.org/10.1177/0891243218809604

Switek, M. (2016). Internal migration and life satisfaction: Well-being paths of young adult migrants. Social Indicators Research, 125(1), 191-241. https://doi.org/10.1007/s11205-014-0829-X

Trappe, H., Pollmann-Schult, M., \& Schmitt, C. (2015). The rise and decline of the male breadwinner model: Institutional underpinnings and future expectations. European Sociological Review, 31(2), 230-242. https://doi.org/10.1093/esr/jcv015

Trappmann, M., Gramlich, T., \& Mosthaf, A. (2015). The effect of events between waves on panel attrition. Survey Research Methods. https://doi.org/10.18148/SRM/2015.V9I1.5849

van Damme, M., Krapf, S., \& Wagner, M. (2018). Housing density and its consequences for couples in Germany: Staying, moving, or breaking up? Paper presented at the Divorce Conference 2018 in Tel Aviv.

Vidal, S., Perales, F., Lersch, P. M., \& Brandén, M. (2017). Family migration in a cross-national perspective: The importance of within-couple employment arrangements in Australia, Britain, Germany, and Sweden. Demographic Research, 36, 307-338.

Voicu, M. (2017). Diversity and family: An inquiry into the effects of ethnic, linguistic, and religious fractionalization on family values. Ethnic and Racial Studies, 40(14), 2501-2519. https://doi.org/10. 1080/01419870.2016.1250936

Wagner, M., Mulder, C. H., Weiß, B., \& Krapf, S. (2019). The transition from living apart together to a coresidential partnership. Advances in Life Course Research, 39, 77-86. https://doi.org/10.1016/j. alcr.2018.12.002

Wolbring, T. (2017). Home sweet home! Does moving have (lasting) effects on housing satisfaction? Journal of Happiness Studies, 18(5), 1359-1375. https://doi.org/10.1007/s10902-016-9774-5

Publisher's Note Springer Nature remains neutral with regard to jurisdictional claims in published maps and institutional affiliations. 